\title{
Expression of Concern to: Does ovary need D-chiro-inositol?
}

Rosalbino Isabella ${ }^{1 *}$ and Emanuela Raffone ${ }^{2}$

Pursuant to a decree of the Tribunal of Catania, First Civil Section, LJ Pharma SRL obtained an ex Parte order. The Judge orders BioMed Central Ltd, in the person of the legal representative pro tempore to implement the remedy of the retraction notice on the study, signed by Isabella and Raffone, "Does Ovary need d-chiro-inositol?", published in 2012 in the specialized journal Journal of Ovarian Research [1].

\section{Author details}

${ }^{1}$ C.I.S. Reproductive Medicine, Lamezia Terme, Italy. ${ }^{2}$ Obstetrics and

Gynecology Department, G. Martino Hospital, Messina, Italy.

Received: 4 July 2018 Accepted: 4 July 2018

Published online: 05 July 2018

\section{Reference}

1. Isabella R, Raffone E. Does ovary need D-chiro-inositol? Journal of Ovarian Research. 2012;5:14.

\footnotetext{
* Correspondence: rosalbinoisabella@gmail.com

'C.I.S. Reproductive Medicine, Lamezia Terme, Italy
} 